\title{
Soluble expression and characterization of a GFP-fused pea actin isoform (PEAc1)
}

\author{
Ai Xiao LIU*, Shao Bin ZHANG*, Xiao Jing XU, Dong Tao REN, Guo Qin LIU**
}

State Key Laboratory of Plant Physiology and Biochemistry, College of Biological Science, China Agricultural University, Beijing 100094, China.

\begin{abstract}
A pea actin isoform PEAc1 with green fluorescent protein (GFP) fusion to its C-terminus and His-tag to its Nterminus, was expressed in prokaryotic cells in soluble form, and highly purified with Ni-Chelating Sepharose ${ }^{\mathrm{TM}}$ Fast Flow column. The purified fusion protein (PEAc1-GFP) efficiently inhibited DNase I activities before polymerization, and activated the myosin Mg-ATPase activities after polymerization. The PEAc1-GFP also polymerized into green fluorescent filamentous structures with a critical concentration of $0.75 \mu \mathrm{M}$. These filamentous structures were labeled by TRITC-phalloidin, a specific agent for staining actin microfilaments, and identified as having $9 \mathrm{~nm}$ diameters by negative staining. These results indicated that PEAc1 preserved the essential characteristics of actin even with His-tag and GFP fusion, suggesting a promising potential to use GFP fusion protein in obtainning soluble plant actin isoform to analyze its physical and biochemical properties in vitro. The PEAc1-GFP was also expressed in tobacco BY2 cells, which offers a new pathway for further studying its distribution and function in vivo.
\end{abstract}

Keywords: actin isoform, polymerization, DNase I inhibition, myosin Mg-ATPase activation, expression.

\section{INTRODUCTION}

Actin is one of the major cytoskeleton proteins and plays important roles in a variety of subcellular processes, such as cytoplasmic streaming [1-3], organellar and nuclear positioning [4-6], cellular morphogenesis [7-9], and cell division [10-12]. The diversity of these functional roles reflects the diversity in plant actin gene families $[13,14]$.

In plants, actins are encoded by gene families that are much more diverse than those in other eukaryotes. Eight actin homologues in Arabidopsis are grouped into two major phylogenetic classes (vegetative and reproductive) and five subclasses were found $[13,14]$. Three kinds of actin isoform genes (PEAc1, PEACII, PEACIII) were found in pea (Pisum sativum L) [15]. PEAcl has the highest identity about $97.3 \%$ with $A C T 7$ among all the actin isoforms of Arabidopsis (DNA Star). Actin isovariants in plants differ in their expression patterns [16-18], and their dynamics are thought to expand the biochemical processes

\footnotetext{
"These authors contributed equally to this work.

${ }^{* *}$ Correspondence: Guo Qin LIU,

Tel: 86-10-62893438, Fax: 86-10-62891332

E-mail: Liu@cau.edu.cn
}

that buffer the responses of plant cells to internal or external signals[14]. Recently, Kandasarmy et al [19] demonstrated that a plant actin isovariant (ACT7) was induced by auxin and was required for normal callus formation. Further understanding of the specificity in biochemical and cell biological characteristics among actins will require a detailed analysis of each kind of actin isoform.

To elucidate the biochemical properties of plant actin, previous studies have focused on actin purification directly from plant materials [20,21]. The low abundance of actin and the presence of proteases in most plant materials made it difficult to obtain sufficient highly purified actin for in vitro studies [22, 23]. Although some methods have been developed to get relatively high yields of actin from plant pollens $[24,25]$, it is still very difficult to purify actin (especially actin isoforms) from most of the plants [26]. Expression of proteins in E. coli has greatly facilitated our understanding of physicochemical properties of proteins including plant actin binding protein [27, 28]. Unfortunately, there is still no successful example of the expression of active eukaryotic actin in E. coli. The failure is generally considered to be due to the lack of appropriate molecular chaperones for proper actin folding [29, 30] and that actin is unable to spontaneously refold into a functional 
form after denaturation.

Microinjection of fluorescent phalloidin as a specific probe for F-actin has shown to be an effective method for in vivo labeling of actin filaments in living plant cells [10, 31], but unsuitable for labeling specific actin isoforms. Since GFP was used as a non-invasive labeling marker to localize specific proteins in living cells [32], GFP fusion has been successfully applied to light up microfilaments in animal cells [33-35]. Kost et al [36] observed the distribution of microfilaments in tobacco pollens and suspension cells with the assistance of GFP-labeled talin, one of the microfilament binding proteins, and found GFPfused talin satisfactorily revealed the location of microfilaments in cells.

It is challenging to elucidate the biochemical characteristics and dynamic distributions for each kind of plant actin isoform. Here we report that PEAc1, a pea tendril actin isoform, was expressed with GFP fusion in soluble form in E. coli, and the product was purified and physicoand biochemically characterized. The fusion protein was also expressed in tobacco suspension cells.

\section{MATERIALS AND METHODS}

\section{Materials}

The PEAc1 cDNA was cloned from pea (Pisum sativum L.) tendril [37] (GenBank accession number X67666). The prokaryotic expression vector pET-30 $\left(\mathrm{a}^{+}\right)$was from Novagen Inc. (Madison, $\mathrm{WI}$ ) and the plant binary vector pBI121 was from Clontech (Palo Alto, CA). Primers were synthesized by the Gene Center of Institute of Microbiology, Chinese Academy of Science (Beijing, China). Ni-Chelating Sepharose ${ }^{\mathrm{TM}}$ Fast Flow was purchased from Amersham Pharmacia (Uppsala, Sweden). Monoclonal mouse anti-GFP and anti-His-tag antibodies, and HRP-conjugated goat anti-mouse (or anti-rabbit) IgG were from Sigma (St. Louis, MO). The rabbit antiserum against PEAc1 was prepared in our lab using PEAc1 whole protein. DNA restriction enzymes, ligase and polymerase were from Bio-Lab (Hercules, CA). DNA purification kit was from Shanghai Sangon Company (Shanghai, China).

\section{Plasmid construction}

The coding region (1131 bp) of PEAcl was amplified from PEAcl full length cDNA [37] using two primers containing restriction sites (BamHI-forward, 5'-gcggatccatggccgatgctgaggatat-3'; Kpn I-reverse, 5'-gcggtaccgaagcattttctgtggacaat-3'). The GFP coding region (723 bp) was PCR amplified from psm-RS-GFP (donated by American Arabidopsis Biological Resource Center) using two primers (Kpn Iforward, 5'-gcggtaccatgagtaaaggagaagaact-3'; SacI-reverse, 5'gcgagctcttatttgtatagtt-3'). The restriction fragments corresponding to PEAc1 and GFP were inserted into BamHI/SacI site of pET30 $(\mathrm{a}+)$. The recombined plasmid was transformed into E.coli BL21 cells. pET-GFP vector containing the fragment of GFP served as a control. All constructs were verified by sequencing. For the expression in tobacco BY-2 cells, the PEAc1-GFP fusion gene was inserted into $\mathrm{BamHI} / \mathrm{SacI}$ site of pBI121 to yield pBAc1-GFP vector.

\section{Prokaryotic expression and purification of recombinant} protein

Transformed E. coli BL21 cells were cultured in liquid LB medium (with $50 \mu \mathrm{g} / \mathrm{ml}$ kanamycin) at $37^{\circ} \mathrm{C}$ to $\mathrm{OD}_{600}=0.6$, then at $25^{\circ} \mathrm{C}$ to $\mathrm{OD}_{600}=0.8$. The expression of PEAc1-GFP was induced by addition of $0.25 \mathrm{mM}$ isopropyl- $\beta$-D-thiogalactoside (IPTG) and a further shaking at $22^{\circ} \mathrm{C}$ for $20 \mathrm{~h}$. After identification under the fluorescence microscope, the cells were harvested and sonicated on ice in buffer A ( $2 \mathrm{mM}$ Tris, $\mathrm{pH} 8.0,0.2 \mathrm{mM} \mathrm{CaCl}_{2}, 0.2 \mathrm{mM}$ ATP, $0.5 \mathrm{mM}$ PMSF, $0.2 \mathrm{mM} \mathrm{NaN}_{3}$ ). All subsequent steps were performed at $4^{\circ} \mathrm{C}$. The cell extracts were centrifuged at $10,000 \mathrm{~g}$ for 20 $\mathrm{min}$. The resultant supernatants were applied to a self-packed $1 \mathrm{ml}$ Ni-resins pre-equilibrated with buffer A. Following serial washing with 10,50 and $100 \mathrm{mM}$ imidazole (in buffer A, $5 \mathrm{ml}$ each), the Histagged fusion protein was eluted with $5 \mathrm{ml} 300 \mathrm{mM}$ imidazole (in buffer A). To obtain the GFP protein, the cells containing pET-GFP vector were induced by $0.1 \mathrm{mM}$ IPTG and cultured at $37^{\circ} \mathrm{C}$ for $3 \mathrm{~h}$. Based on SDS-PAGE and western blot analysis, the fractions containing purified fusion protein were pooled and dialyzed against buffer B (buffer A plus $0.5 \mathrm{mM}$ DTT). The concentration of protein extracts was determined using the Bio-Rad protein assay kit with bovine serum albumin (BSA) as the standard.

\section{Polymerization in vitro and critical concentration determi- nation}

Actin polymerization and steady state polymer levels were measured by $90^{\circ}$ light scattering [38]. Fluorescence changes were monitored in a fluorescence spectrophotometer (F-4500, Hitachi) with the excitation monochromator set at $450 \mathrm{~nm}$ and the emission monochromator set at the same wavelength. Before polymerization, the freshly purified PEAc1-GFP was clarified by centrifugation at $200,000 \mathrm{~g}$ for $90 \mathrm{~min}$ at $4^{\circ} \mathrm{C}$. The polymerization of $80 \mu \mathrm{g} / \mathrm{ml}$ (about $1.1 \mu \mathrm{M})$ PEAc1-GFP monomers was initiated by the addition of $\mathrm{KCl}$ to $50 \mathrm{mM}$ and $\mathrm{MgCl}_{2}$ to $2 \mathrm{mM}$ in buffer $\mathrm{B}$ at $21^{\circ} \mathrm{C}$. For green fluorescence detection of polymerized products, each sample was directly observed under a fluorescent microscope (LEICA, DMIRB) equipped with Cooled CCD (Photometrix, KAF1400-G2, Sensys).

For critical concentration determination, samples containing 1-6 $\mu \mathrm{M}$ chicken muscle actin or PEAc1-GFP in $8 \mathrm{ml}$ of buffer B were prepared. Then at time zero, salts were added to give a final concentration of $2 \mathrm{mM} \mathrm{MgCl}_{2}$ and $50 \mathrm{mM} \mathrm{KCl}$ in $7 \mathrm{ml}$ of reaction systems. The remaining $1 \mathrm{ml}$ of each sample without these two salts was used as control. The polymerization was allowed to proceeding at $4^{\circ} \mathrm{C}$ overnight (approximately $16 \mathrm{~h}$ ). The amount of polymerized filaments of each reaction sample at steady state equilibrium was measured in F-4500.

\section{Inhibition of DNase I with PEAc1-GFP monomers}

The inhibition assay of DNase I (Roche) activities by PEAc1GFP monomers was according to the procedure of Fox et al [39]. $40 \mu \mathrm{M}$ PEAc1-GFP monomers or chick muscle G-actin was prepared in $1 \mathrm{ml}$ reaction system (125 mM Tris, $\mathrm{pH} 7.5,5 \mathrm{mM} \mathrm{MgCl}_{2}$, $2 \mathrm{mM} \mathrm{CaCl}_{2}, 3 \mathrm{mM} \mathrm{NaN}_{3}$ ). The substrate, salmon sperm DNA (Sigma), was added to a final concentration of $0.1 \mathrm{mg} / \mathrm{ml}$. The reaction was started by the addition of an equal molecular amount DNase I at $21^{\circ} \mathrm{C}$. The optical absorption was recorded at $260 \mathrm{~nm}$ for 30 min with a Nucleic Acid and Protein Analyzer (Beckman, DU640). 
A

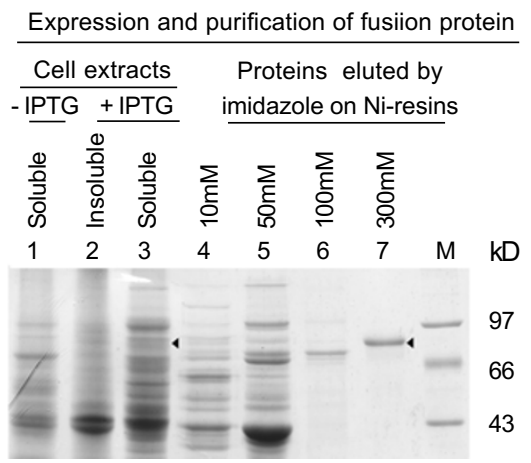

B

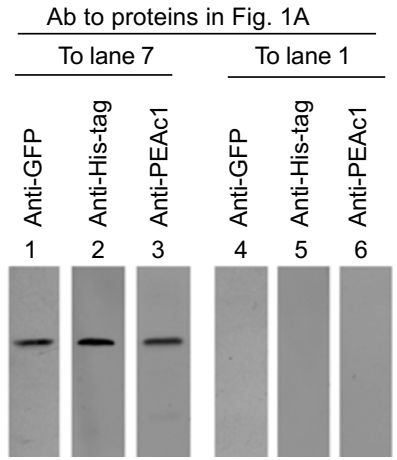

Fig. 1 Expression and purification of the recombinant PEAc1-GFP protein from E. coli cells. (A) The Proteins were prepared from IPTGtreated or untreated E.coli cells. The soluble fraction from IPTG-treated extracts was passed through a Ni-Chelating Sepharose ${ }^{\mathrm{TM}}$ Fast Flow column, and then washed and eluted as described in Materials and Methods. The proteins were separated on a $10 \%$ SDS-polyacrylamide gel and stained with Coomassie blue. M, Marker proteins with masses in kilodaltons. (B) The highly purified PEAc1-GFP was determined by immunoblot analysis using anti-GFP monoclonal antibodies, anti-his-tag monoclonal antibodies, and polyclonal antiserum against PEAc1, respectively. Those without the treatment of IPTG served as negative control.

\section{Activation of muscle myosin Mg-ATPase activity by filamentous P EAc1-GFP}

ATPase activity of myosin prepared from the chick muscle, was measured according to the method of Pollard [40] with some modifications. The reaction mixtures for the assay of $\mathrm{Mg}$-ATPase activity contained $38 \mathrm{mM}$ imidazole, $\mathrm{pH} 7.0,25 \mathrm{mM} \mathrm{KCl}, 0.8 \mathrm{mM}$ $\mathrm{MgCl}_{2}, 0.1 \mathrm{mM} \mathrm{CaCl}_{2}$, and $0.06 \mathrm{mg} / \mathrm{ml}$ myosin, in the presence or absence of $0.5 \mu \mathrm{M}$ filamentous PEAc1-GFP or muscle F-actin. Reactions were started by the addition of ATP $(2 \mathrm{mM})$. The inorganic phosphate in reaction mixtures was determined as described by Le Bel et al [41]. Chick muscle F-actin was prepared by the methods of Pardee and Spudich [42].

\section{SDS-PAGE and Western blot analysis}

Proteins were separated on 10\% SDS-PAGE [43], and analyzed by western blot according to Towbin et al [44]. Mouse anti-His-tag (with 1:6000 dilute) and anti-GFP (with 1:8000 dilute) monoclonal antibodies and rabbit anti-PEAc1 serum (with 1:4000 dilute) were used as the primary antibodies, while goat anti-mouse (or anti-rabbit) IgG-conjugated with HRP (with 1:4000 dilute) were used as the secondary antibodies. The membranes were visualized by using an enhanced Lumi-Light western blotting Substrate kit (Roche, Indianapolis, IN), following the manufacturer's instructions.

\section{Phalloidin-staining of filamentous PEAc1-GFP}

The polymerized samples were dropped on poly-L-lysine (Sigma) coated slides, stained with tetramethyrhodamine isothiocyanate (TRITC)-phalloidin ( $5 \mu \mathrm{g} / \mathrm{ml}$ in buffer B, plus $50 \mathrm{mM} \mathrm{KCl}$ and $2 \mathrm{mM}$ $\mathrm{MgCl}_{2}$ ) for $30 \mathrm{~min}$ at room temperature in a wet-atmosphere. Then, the same volume of fluorescence antifade reagent (Bio-Rad) was added. The polymerization was monitored with a microscope as described above.

\section{Eukaryotic expression of PEAc1-GFP in tobacco BY2 cells}

The pBAc1-GFP plasmid was transformed into tobacco suspension BY2 cells by microprojected bombardment with a Bio-Rad PDS-1000/He. The cells were cultured in MS medium supplemented with $0.6 \mu \mathrm{g} / \mathrm{ml}$ 2, 4-D, pH 5.8, and $100 \mu \mathrm{g} / \mathrm{ml} \mathrm{Kanamycin} \mathrm{at} 25^{\circ} \mathrm{C}$. The GFP fluorescence from PEAc1-GFP fusion proteins was monitored.

\section{Electron microscopy}

For the measurement of filament diameter, the samples containing polymerized PEAc1-GFP were applied to formvar grids and negatively stained with $2 \%$ uranyl acetate. The specimens were visualized by using a Hitachi $\mathrm{H} 7500$ electron microscope.

\section{RESULTS}

\section{Prokaryotic soluble expression and purification of PEAc1-GFP fusion protein}

The coding region of $P E A c 1$ was $P C R$ amplified, with GFP fused to its C-terminus, and a $6 \times$ his-tag fused to its $\mathrm{N}$-terminus. The prokaryotic expression plasmid was introduced into E. coli cells. For the expression of the fusion gene, different inducing conditions were tested. The strong green fluorescence could be detected after the cells were induced with $0.25 \mathrm{mM}$ IPTG at $22^{\circ} \mathrm{C}$ for $20 \mathrm{~h}$ (data not shown). Protein analysis by SDS-PAGE and Western blot showed that $74.3 \mathrm{kD}$ fusion proteins were mainly expressed in soluble form (Fig. 1A, shown by arrow). The results show that the soluble fusion protein could be highly purified in large amounts (milligram fusion quantities 

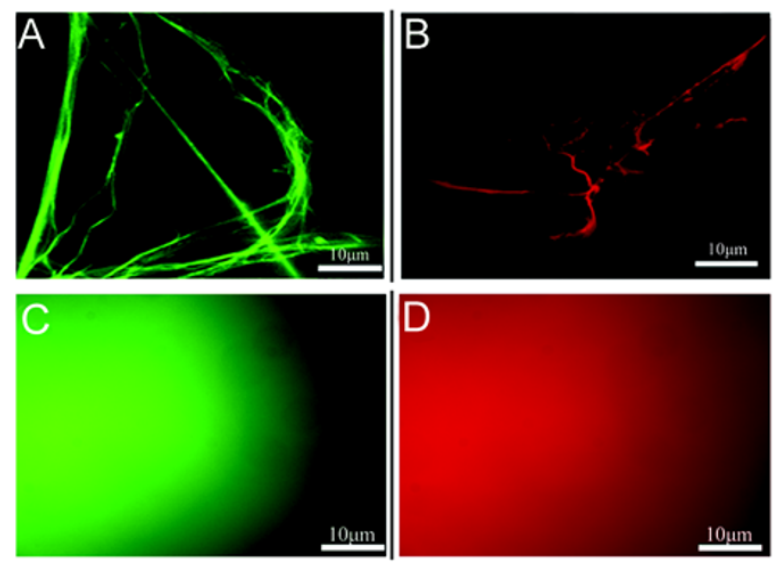

Fig. 2 The highly purified soluble PEAc1-GFP fusion proteins could polymerize to F-actin-like structures. (A) After polymerization in buffer B containing $50 \mathrm{mM} \mathrm{KCl}$ and $2 \mathrm{mM} \mathrm{MgCl}_{2}$, filamentous green fluorescence could be observed directly under fluorescent microscope by exciting at blue light; (B) The PEAc1-GFP filaments with green fluorescence could be stained by TRITCphalloidin. (C) and (D) were prepared from non polymerized PEAc1GFP, serving as controls to A and B respectively.

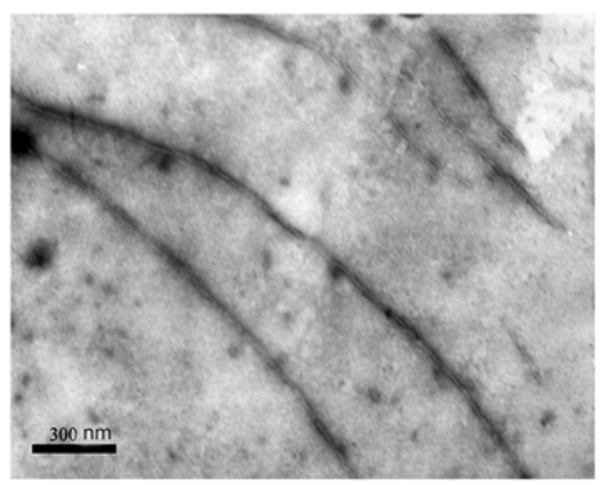

Fig. 3 The negatively stained filaments polymerized from PEAc1GFP show a diameter of $9 \mathrm{~nm}$ under transmission electron microscope.

of protein from a liter liquid culture) by an affinity column (Fig. 1A, lane 7, shown by arrow). Western blot analysis demonstrated that the purified $74.3 \mathrm{kD}$ polypeptides could be recognized by anti-GFP monoclonal antibodies, anti-his-tag, and anti-PEAc1 polyclonal antibody (Fig. 1B, lanes 1-3); No polypeptides from bacteria before inducing (Fig. 1A, lane 1) could be recognized by any antibodies above (Fig. 1B, lanes 4-6), only the induced $74.3 \mathrm{kD}$ polypeptides in lane 3 (Fig. 1A) could react with these antibodies (data not shown) giving the same results as Fig. 1B (lanes 1-3).
A

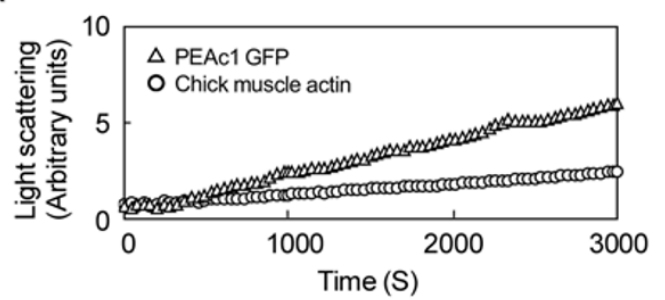

B

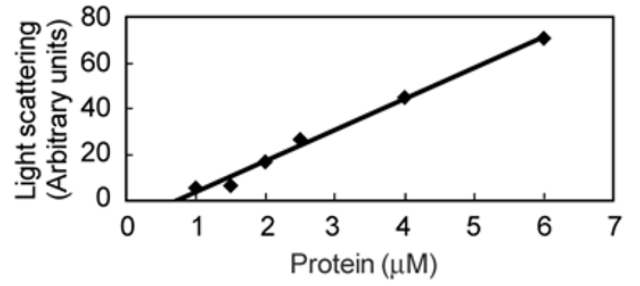

Fig. 4 Measurement of assembly time-course and critical concentration of PEAc1-GFP. (A) Time courses for PEAc1-GFP and muscle actin polymerization were measured by $90^{\circ}$ light scattering at $21^{\circ} \mathrm{C}$ at $450 \mathrm{~nm}$. The polymerization of $80 \mu \mathrm{g} / \mathrm{ml}$ PEAc1-GFP monomers (open triangle) in buffer $\mathrm{B}$ was initiated by adding $\mathrm{KCl}$ to $50 \mathrm{mM}$ and $\mathrm{MgCl}_{2}$ to $2 \mathrm{mM}$, and the light scattering was recorded for $50 \mathrm{~min}$, the chick muscle actin was used as control (open circle). (B) The critical concentration of PEAc1-GFP polymerization determined by measurement of light scattering was $0.75 \mu \mathrm{M}$. PEAc1-GFP with different concentration was polymerized in assembly buffer for overnight. The steady-state light scattering was measured and normalized against samples without salt.

\section{PEAc1-GFP fusion proteins can polymerize into a filamentous structure in vitro}

Under actin polymerization condition, purified PEAc1GFP fusion proteins polymerized to form green fluorescence filamentous structures (blue light excitation) as shown in Fig. 2A; and the filamentous structures could be specifically stained by TRITC-phalloidin (green light excitation) as shown in Fig. 2B.

The Electron micrographs from negatively staining demonstrated that the diameter of the filamentous PEAc1GFP is about $9 \mathrm{~nm}$ (Fig. 3), similar as F-actin (7-9 nm) $[45,46]$.

These results above indicate that the prokaryotic expressed PEAc1-GFP fusion proteins were able to polymerize into F-actin-like structures in vitro.

\section{PEAc1-GFP fusion proteins polymerized with essentially normal polymerization dynamics}

The polymerization dynamics and the critical concentration determination of PEAc1-GFP were monitored at $450 \mathrm{~nm}$. The light scattering curves indicated that the amount of filaments at steady state equilibrium was 
A

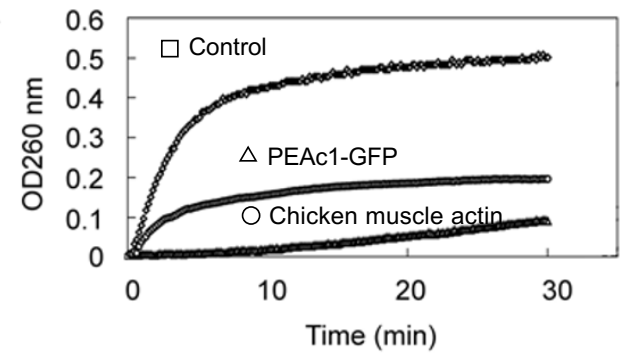

B

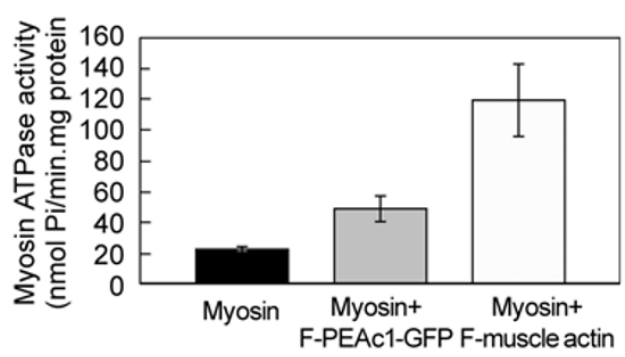

dependent on the initial protein monomer concentration, and that the polymerization dynamics of PEAc1-GFP were similar to that of animal muscle actin (Fig. 4A). Under this condition, the polymerization usually took more than $3 \mathrm{~h}$ to attain equilibrium (data not shown).

As shown in Fig. 4B, the point at which a line through these data intersected the $\mathrm{X}$-axis is a indication of critical concentration. The average critical concentration for PEAc1GFP is $0.75 \pm 0.02 \mu \mathrm{M}(\mathrm{n}=7)$, a little higher than chicken muscle actin critical concentration $0.56 \pm 0.02 \mu \mathrm{M}$ measured under the same conditions.

As a control, we also purified GFP fused with $6 \times$ his-tag (about $30 \mathrm{kD}$, data not shown), and determined its spectrum characteristics: the absorb peak is at $489 \mathrm{~nm}$ (with UV640); the maximum fluorescence exciting wavelength is $490 \mathrm{~nm}$; the emission wavelength is $510 \mathrm{~nm}$ (with F-4500), all of which are far away from $450 \mathrm{~nm}$. At the same polymerization condition, the value of light scattering of GFP protein at $450 \mathrm{~nm}$ did not change (data not shown). So we could draw a conclusion that the method used to determine the polymerization of actin could also be adapted to PEAc1GFP, and the polymerization characters of PEAc1-GFP came from PEAc1, but not GFP.

\section{The purified PEAc1-GFP fusion proteins inhibit DNase I activity and stimulate myosin Mg-ATPase activity}

The inhibition of DNase I activities by active G-actin monomer through binding to DNase I and forming a highaffinity 1:1 complex is an important character of G-actin. In our assay, the inhibition of DNase I activity was obvious
Fig. 5 PEAc1-GFP inhibits the activity of DNase I before polymerization and stimulates Mg-ATPase activity of chick muscle myosin after polymerization. (A) The reaction kinetics of DNase I hydrolyzing DNA in presence of PEAc1GFP, chicken muscle actin or DNase I only (curve1) (control). The concentration of all the protein included was $40 \mu \mathrm{M}$. The dynamic optical absorption was recorded at $260 \mathrm{~nm}$ for $30 \mathrm{~min}$ after zero point was adjusted as soon as DNase I was added with a Nucleic Acid and Protein Analyzer. (B) The ATPase activity of chicken muscle myosin in the presence of filamentous PEAc1-GFP, chicken muscle actin or the myosin only (control). Experiments were repeated for 3 times, with 3 paralell tests for each.

when purified PEAc1-GFP fusion protein monomers were added to a DNase I solution at about a 1:1 molecular proportion (Fig. 5A middle). The dynamic profile of PEAc1-GFP is similar to chick muscle G-actin. The GFP alone did not show an obvious effect on DNase I activity at the same condition (data not shown). The result indicates that the fusion protein of actin isoform PEAc1 still maintains its property to inhibit DNase I activity.

Stimulating myosin Mg-ATPase activity is another important characteristic of actin in filaments [47]. To know if PEAc1-GFP filamentous structures have this ability, the Mg-ATPase activities of purified chick muscle myosin were measured in the presence or absence of polymerized PEAc1-GFP filaments, using muscle F-actin as a positive control. The results shown in Fig. 5B demonstrated that the basic Mg-ATPase activity of chick muscle myosin was about $23.3 \pm 21.76(\mathrm{n}=3) \mathrm{nM} \mathrm{Pi} /$ $\mathrm{mg}$ protein $\mathrm{min}$ (black column) in our experimental conditions, and $49.42 \pm 8.23(\mathrm{n}=3)$ after the addition of polymerized PEAc1-GFP filaments to the reaction (gray column), and $119.49 \pm 23.32(n=3)$ for polymerized chicken muscle actin (white column). The 2-fold stimulation of activity of myosin Mg-ATPase indicates that the polymerized filaments of the actin fusion proteins are able to interact with myosin motor molecules $(P<0.005)$.

\section{PEAc1-GFP fusion protein was expressed in tobacco cell suspension BY2 line}

The recombinant plasmid pBAc1-GFP was transformed into the tobacco cell suspension BY2 line for eukaryotic expression. Stable expression was observed 


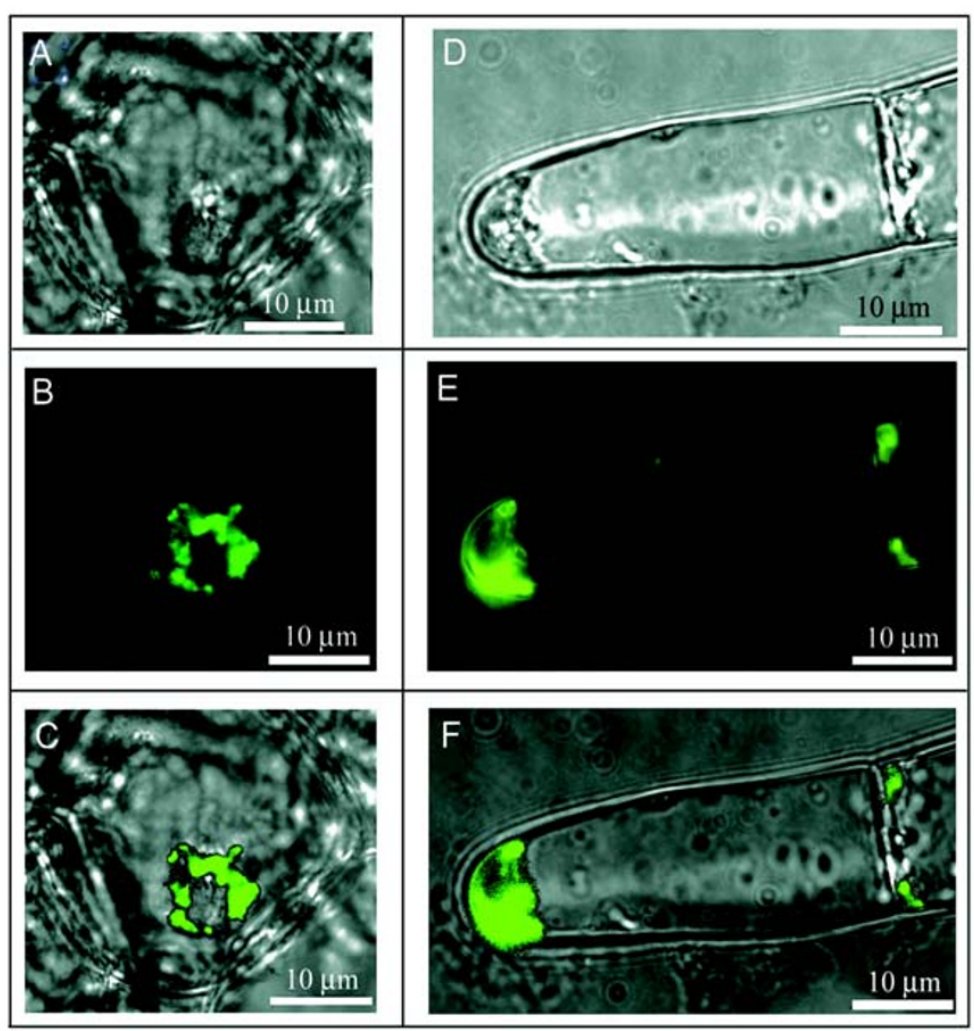

Fig. 6 Recombinant PEAc1-GFP protein was expressed stably in tobacco BY2 suspension cells. (A) and (D) are transmitted light images of transformed BY2 cells; $(\mathbf{B})$ and $(\mathbf{E})$ are images of green fluorescence from the same view sections of $\mathbf{A}$ and $\mathbf{D} ;(\mathbf{C})$ and $(\mathbf{F})$ show merged images from the above ones. The green fluorescence was observed to be surrounding the nuclei of normal cells and near the tip and cell wall of extending tobacco cells.

in cells selected with kanamycin. After several subcultures, PEAc1-GFP fluorescence was mainly found surrounding the nuclei of normal cells (Fig. 6A-C), and concentrated near the tip and cell wall of extending cells (Fig. 6D-F). The distribution of PEAc1-GFP in tobacco cells suggests that the GFP fusion does not affect the expression of PEAc1 in eukaryotic cells, which makes a foundation for a detailed study into the distribution or function of PEAc1 in vivo.

\section{DISCUSSION}

In this study, we have successfully purified the soluble expression product of PEAc1, one isoform of pea tendril actins, using GFP fusion. Evidences from fluorescence study, dynamic and biochemical analysis showed that the fusion proteins retain the basic physical and biochemical properties of actin. Ni-Chelating Sepharose ${ }^{\mathrm{TM}}$ Fast Flow chromatography and gradient washing with buffers containing different levels of immidazole purified a specific His-tagged actin PEAc1 fusion protein (Fig. 1). Specifically, more than 1 milligram of actin fusion protein with high purity could be rapidly obtained from 1 liter of bacteria culture. Notably the purified product is a kind of plant actin isoform that is very difficult to obtain by normal biochemical isolation [26]. The soluble expression and rapid purification of pea actin isoform PEAc1 provides a relatively simple method for comparing the biochemical properties among actin isoforms in vitro. Furthermore, the GFP labeling of actin isoform might be optimal for motility assays in vitro and for investigating the dynamic distribution in vivo.

The ability to bind to DNase I molecules is a basic physicochemical property of G-actin monomers, whereas the ability to stimulate myosin activity and to bind to phalloidin is the property of polymeric actin. We have shown that the purified monomeric PEAc1-GFP could bind to DNase I and inhibit DNase I activity using salmon sperm DNA as substrate (Fig. 5A). Also, polymerized PEAc1GFP filaments stimulated muscle myosin ATPase activity up to two-fold (Fig. 5B). Under physiological ionic 
conditions, PEAc1-GFP polymerized with kinetics similar to those of skeleton muscle actin (Fig. 4A), and with a critical concentration of $0.75 \mu \mathrm{M}$ (Fig. 4B). The critical concentration was a little higher than that of muscle $\alpha$ actin, but consistent with the result of $0.6 \mu \mathrm{M}$ of pollen actin [25]. The filamentous structures could be seen directly under the fluorescence microscope because of the fusion with GFP and could be specifically stained with TRITC-phalloidin (Fig. 2A-B). The filamentous PEAc1GFP was further viewed ultrastructurally by negative staining, showing long straight filaments with an average diameter of about $9 \mathrm{~nm}$ (Fig. 3). Although it is known that the prokaryotic cytosol is unable to provide a post-translational modification found on most forms of actin: the methylation of histidine 73 [48], our results indicated that the bacteria expressed PEAc1-GFP proteins still retained their basic physicochemical properties, which was consistent with previous foundings that purified Dictyostelium discoideum actin from highly insoluble aggregates expressed in E. coli held the ability both to polymerize and to bind to DNase I [48]. Our results in this paper also provided new evidence that GFP fusion neither disturbs the polymerization ability of actin isoform PEAc1 monomers, nor influences its interaction with DNase I and myosin motor molecules.

Actin isotypes encoded by a relatively ancient and highly divergent multigene family differ in their functions and expression patterns, and play different roles in different tissues and development stages [13, 14, 17, 18]. Although the tissue-specific expression of actin isoforms can be detected by anti-peptides antibodies against specific peptides of each kind of actin isoforms [49], their dynamic distribution patterns in living cells keep relatively unknown. GFP has been extensively used as a reporter gene and a protein label for its ability to reveal real time dynamics of proteins in vivo without destroying the cell structure. Some successful examples have been shown on the distribution and dynamics of microfilaments in Dictyo-stelium discoideum [50], mammalian cells [34] and yeast [51]. In our study, GFP was sucessfully used as a molecular "flag" to label PEAc1 and thus allow further studies on its characterizaion. The presence of the expressed fusion proteins in cells indicated that the GFP fusion did not affect the expression of PEAc1 in eukaryotic cells. Furthermore, in different cell lines or same cells at different stages, the distribution and state of actin proteins are always in changing, sometimes in filaments, sometimes in bundles even networks, to play different roles in cell activities [11]. Direct observation of the dynamic state of each actin isoform in plant cells could help us in further understanding the detailed roles of plant actins. Our results suggest that it is promising to use GFP fusion to analyze the physi- cal and biochemical properties of plant actin isoforms in vitro, and possibly its dynamic distributions or biological functions in vivo.

\section{ACKNOWLEDGMENTS}

We are most grateful to Dr. Richard B. Meagher (The Genetics Department, University of Georgia) for his valuable suggestions. We thank Drs. N. Ronald Morris and Richard S Nowakowski (UMDNJ-Robert Wood Johnson Medical School) for their critical reading the manuscript. This research was supported by grants from the National Natural Science Foundation of China (No. 30170457, 39970358 to Guo Qin LIU, and No. 30270664 to Dong Tao REN) and from The Education Ministry of China (No. 2000001911) to Guo Qin LIU.

Received, Dec 8, 2003

Revised, May 28, 2004

Accepted, Jun 8, 2004

\section{REFERENCES}

1 Kuroda K. Cytoplasmic streaming in plant cells. Int Rev Cytol 1990; 121:267-307.

2 Williamson RE. Organelle movements. Annu Rev Plant Physiol Plant Mol Biol 1993; 44:181-202.

3 Staiger CJ, Yuan M, Valenta R, et al. Microinjected profilin affects cytoplasmic streaming in plant cells by rapidly depolymerizing actin microfilaments. Curr Biol 1994; 4:215-9.

4 Katsuta J, Shibaoka H. The roles of the cytoskeleton and the cell wall in nuclear positioning in tobacco BY-2 cells. Plant Cell Physiol 1988; 29:403-13.

5 Lloyd CW. The plant cytoskeleton. Curr Opin Cell Biol 1989; 1: 30-5.

6 Staiger CJ, Lloyd CW. The plant cytoskeleton. Curr Opin Cell Biol 1991; 3:33-42.

7 Miller DD, de Ruijter NCA, Bisseling T, Emons AMC. The role of actin in root hair morphogenesis: Studies with lipochito-oligosaccharide as a growth stimulator and cytochalasin as an actin perturbing drug. Plant J 1999; 17:141-54.

8 Szymanski DB, Marks MD, Wick SM. Organized F-actin is essential for normal trichome morphogenesis in Arabidopsis. Plant Cell 1999; 11:2331-47.

9 Gibbon BC, Kovar DR, Staiger CJ. Latrunculin B has different effects on pollen germination and tube growth. Plant Cell 1999; 11:2349-63.

10 Schmit AC, Lambert AM. Microinjected fluorescent phalloidin in vivo reveals the F-actin dynamics and assembly in higher plant mitotic cells. Plant Cell 1990; 2:129-38.

11 Hepler PK, Cleary AL, Gunning BES, et al. Cytoskeletal dynamics in living plant cells. Cell Biol Int 1993; 17:127-42.

12 Staehelin LA, Hepler PK. Cytokinesis in higher plants. Cell 1996; 84:821-4

13 McDowell JM, Huang S, McKinney EC, et al. Structure and evolution of the actin gene family in Arabidopsis thialiana. Genetics 1996; 142:587-602.

14 Meagher RB, McKinney EC, Kandasamy MK. Isovariant dy- 
namics expands and buffers the responses of complex systems: The diverse plant actin family. Plant Cell 1999; 11:1-12.

$15 \mathrm{Hu} \mathrm{SN}$, Yen LF. Sequence analysis of Pea tendril actin isoform II cDNA clones. Chinese Journal of Biochemistry and Molecular Biology 1999; 15:857-60.

16 Hightower RC, Meagher RB. Divergence and differential expression of soybean actin genes. EMBO J 1985; 4:1-8.

17 McElroy D, Rothenberg M, Reece KS, Wu R. Characterization of the rice (Oryza sativa) actin gene family. Plant Mol Biol 1990; 15:257-68.

18 Huang S, An YQ, McDowell JM, et al. The Arabidopsis ACT11 actin gene is strongly expressed in tissues of the emerging inflorescence, and pollen developing ovules. Plant Mol Biol 1997; 33:125-39.

19 Kandasamy MK, Gilliland LU, McKinney EC, Meagher RB. One plant actin isovariant, ACT7, is induced by auxin and required for normal callus formation. Plant Cell 2001; 13:1541-54.

20 Vahey M, Titus M, Trautwein R, Scordilis S. Tomato actin and myosin: Contractile proteins from higher land plant. Cell Motil 1982; 2:131-47.

21 Villanueva MA, Ho SC, Wang JL. Isolation and characterization of one isoform actin from cultured soybean cells. Arch Biochem Biophys 1990; 277:35-41.

22 Meagher RB. Divergence and differential expression of actin gene families in higher plant. Int Rev Cytol 1991; 125:139-63.

23 Meagher RB, Williamson RE. The plant cytoskeleton. In: Meyerowitz E and Somerville C, editors. Arabidopsis. Cold Spring Harbor Laboratory Press: New York 1994:1049-84.

24 Liu X, Yen LF. Purification and characterization of actin from maize pollen. Plant Physiol 1992; 99:1151-5.

25 Ren HY, Gibbon BC, Ashworth SL, et al. Actin purified from maize pollen functions in living plant cells. Plant Cell 1997; 9: 1445-57.

26 Diaz-camino C, Villanueva MA. Purification of multiple functional leaf-actin isoforms from Phaseolus vulgaris L. Biochem J 1999; 343:597-602.

27 Giehl K, Valenta R, Rothkegel M, et al. Interaction of plant profilin with mammalian actin. Eur J Biochem 1994; 226:681-9.

28 Lopez I, Anthony RG, Maciver SK, et al. Pollen specific expression of maize genes encoding actin depolymerizing factor-like proteins. Proc Natl Acad Sci USA 1996; 93:7415-20.

29 Chen X, Sullivan DS, Huffaker TC. Two yeast genes with similarity to TCP-1 are required for microtubule and actin function in vivo. Proc Natl Acad Sci USA 1994; 91:9111-5.

30 Vinh DBN, Drubin DG. A yeast TCP-1-like protein is required for actin function in vivo. Proc Natl Acad Sci USA 1994; 91: 9116-20.

31 Valster AH, Pierson ES, Valenta R, et al. Probing the plant actin cytoskeleton during cytokinesis and interphase by profilin microinjection. Plant Cell 1997; 9:1815-24.

32 Chalfie M, Tu Y, Euskirchen G, Ward WW, Prasher DC. Green fluorescent protein as a marker for gene expression. Science 1994; 263:802-5.

33 Westphal M, Jungbluth A, Heidecker M, et al. Microfilament dynamics during cell movement and chemotaxis monitored using a DFP-actin fusion protein. Curr Biol 1997; 7:176-83.

34 Choidas A, Jungbluth A, Sechi A, et al. The suitability and application of a GFP-actin fusion protein for long-term imaging of the organization and dynamics of the cytoskeleton in mammalian cells. Euro J Cell Biol 1998; 77:81-90.

35 Ballestrem C, Wherle-Haller B, Imhof BA. Actin dynamics in living mammalian cells. J Cell Sci 1998; 111:1649-58.

36 Kost B, Spielhofer P, Chua NH. A GFP-mouse talin fusion protein labels plant actin filaments in vivo and visualizes the actin cytoskeleton in growing pollen tubes. Plant J 1998; 16:393-401.

37 Cao XF, Wang RC, Yen LF, et al. Construction of a pea tendril cDNA library and sequence analysis of a pea actin cDNA, PEAc1. Chin Sci Bull 1994; 39(4):332-7.

38 Frederiksen DW, Cunningham LW. Methods in Enzymology. In Cooper JA, Pollard TD. Methods to measure actin polymerization. Academic Press, New York London. 1982; 85:182-210.

39 Fox JEB, Dockter ME, Phillips DR. An improved method for determing the actin filament content of nonmuscle cells by the DNase I inhibition assay. Anal Biochem 1981; 116:170-7.

40 Pollard TD. Myosin purification and characterization. Methods Cell Biol 1982; 24:333-71.

41 Le Bel D, Poirier GG, Beaudoin AR. A convenient method of ATPase assay. Anal Biochem 1978; 85:86-9.

42 Pardee JD, Spudich JA. Purification of muscle actin. Methods Cell Biol 1982; 24:271-89.

43 Laemmli UK. Cleavage of structural proteins during the assembly of the head of bacteriophage T4. Nature 1970; 227:680-4.

44 Towbin H, Staehelin T, Gordon J. Electrophoretic transfer of proteins from polyacrylamide gels to nitrocellulose sheets: Procedure and some applications. Proc Natl Acad Sci USA 1979; 76:4350-4.

45 Eglman EH. The structure of F-actin, the actin thin filament. J Muscle Res Cell Motil 1985; 6:129-51.

46 Holmes KC, Popp D, Gebhard W, Kabsch W. Atomic model of the actin filament. Nature 1990; 374:44-9.

47 Leadbeater L, Perry SV. The effect of actin on the magnesiumactivated adenosine triphosphatase of heavy meromyosin. Biochem J 1963; 87:233-8.

48 Frankel S, Condeelis J, Leinwand L. Expression of actin in Escherichia coli. J Biol Chem 1990; 265:17980-7.

49 McLean BG, Eubanks S, Meagher RB. Tissue-specific expression of divergent actins in soybean root. Plant Cell 1990; 2:335-44.

50 Pang KM, Lee E, Knecht D. Use of a fusion protein between GFP and an actin-binding domain to visualize transient filamentous-actin structures. Current Biology 1998; 8:405-8.

51 Doyle T, Botstein D. Movement of yeast cortical actin cytoskeleton visualized in vivo. Proc Natl Acad Sci USA 1996; 93: 3886-91. 